\title{
Numerical study on a hybrid mooring system with clump weights and buoys
}

\author{
"Zhiming Yuan ${ }^{\mathrm{a}}$, Atilla Incecik ${ }^{\mathrm{a}}$, Chunyan $\mathrm{Ji}^{\mathrm{b}}$ \\ ${ }^{a}$ Department of Naval Architecture, Ocean \& Marine Engineering, University of Strathclyde, Glasgow, UK \\ ${ }^{\mathrm{b}}$ School of Naval Architecture and Ocean Engineering, Jiangsu University of Science and Technology, Zhenjiang 212003, China
}

\begin{abstract}
A new hybrid mooring system based on the traditional taut mooring lines was proposed in the present study. A series of clump weights were attached to the lower end of each mooring line to form a catenary shape. Some buoys were connected to the upper ends of the lines to reduce the top tension on each mooring line. In order to verify the advantages of this new hybrid system, we investigated the motion responses of a semisubmersible platform moored by the proposed hybrid mooring system. The top tension on the lines was also calculated by using the time domain method. Comparing the results from the taut mooring system, it can be found that the tension on the lines could be reduced by using the present hybrid mooring system, while the motion responses were hardly influenced. Furthermore, a catenary shape was formed at the lower end of each mooring line, which could reduce the requirement of the anti-uplift capacity of the anchors. We also carried out the parametric study to investigate the optimal position and volume of the buoys. The discussions were highlighted on the influence of the water depth.
\end{abstract}

Key words: coupled analysis; time domain; hybrid mooring system; clump weights; buoys

\section{Introduction}

Deep-water floating systems are normally composed of three main components: the floating vessel, the mooring system (the mooring lines and the anchors) and the marine risers, all of which are subjected to the environmental loads. As a critical component, the mooring system guarantees the safety of the working condition of the vessel. For the water depths of up to $1000 \mathrm{~m}$, the most common mooring system is the catenary mooring system, which consists of a group of lines combined of chain and wire rope. For exploration and production in water depth beyond $1000 \mathrm{~m}$, the weight of the mooring line starts to become a limiting factor in the design of the floating system, and then the taut leg mooring system comes forth, which adopts synthetic polymeric ropes as the main section of the lines. In additional to these two popular mooring systems, a hybrid mooring system with buoys and catenary lines has been proposed these years.

There are mainly three aspects which can estimate the performance of a mooring system. The first one is the motion responses of the vessel. A smaller movement of the vessel will bring a better working condition for the floating structures. The second one is the tension on the mooring lines. It is obvious that a smaller tension is preferable in the design. But these two aspects are always incompatible. A smaller movement of the vessel can only be achieved when the mooring lines provide enough restoring forces, which requires a larger tension. The third one is the requirement for the anchor's holding capacity. The piles or suction anchor are required to resist significant vertical loads when there is a vertical component force at the anchor points, which will greatly increase the cost.

\footnotetext{
${ }^{*}$ Corresponding author at: Dep. of Naval Architecture, Ocean \& Marine Engineering, University of Strathclyde. Henry Dyer Building, G4 0LZ, Glasgow, UK.

Tel: + 44 (0)141548 2288. Fax: +44 (0)141552 2879 .

E-mail address: zhiming.yuan@strath.ac.uk
} 
As for the catenary mooring system, the catenary chains or wires rely heavily on their own weight to provide restoring forces. As a result, it will not only increase the production costs, but also bring an increase to the top tension of the lines and enlarge the vertical loads on the vessel when the line is lifted from the sea bottom (Johanning, et al., 2007). This growth in vertical load can be important as it effectively decreases the vessel's useful payload. The restoring forces provided by catenary chain are not adequate to keep a small platform offset. However, the main advantage is that the anchors are only subjected to the horizontal force component since the lower end of the mooring line is resting on the seabed. As for the taut mooring system, the synthetic polymeric ropes can provide large restoring forces through their axial stiffness, which can reduce mean- and low-frequency platform offsets and improve the drilling condition. Meanwhile, the synthetic fibre lines are considerably light, very flexible and can absorb imposed dynamic motions through extension without causing an excessive dynamic tension. But the disadvantage is that the anchors need to handle a very large vertical.

The idea and application of the clump weights on the offshore mooring lines can be found in some previous publications. Finn (1976) proposed a new deep water offshore platform which was called 'the guyed tower', and the platform was held upright by multiple guy lines. Each line has three main portions: (1) A catenary from the fairlead connection at the tower to the clump weight; (2) a clump weight that is relatively massive compared with the cable; and (3) a line and an anchor pile to anchor the line. The clump weight rests almost entirely on the sea bottom during relatively small tower response. However, during the extreme sea state, the clump weights lift off the bottom to form part of an extended catenary from anchor pile to the tower. Morrison and Asce (1983) carried out the analysis for the dynamic properties of the guyed tower mooring lines. However, these researches are limited to the water depth up to $1500 \mathrm{ft}$. Some other component mooring lines with additional sinkers and buoys are proposed recently. Smith and MacFarlane (2001) used catenary equations to solve a three component mooring made up of two lines, connected at a point buoy or sinker where water depth and fairlead tension were given. Vicente et al. (2011) investigated different mooring configurations with slack chain mooring lines of a floating point absorber with or without additional sinkers or floaters. It was found that the different arrangement of the buoys and weights would bring significant differences in terms of average and maximum tensions on the mooring cables. Hong and Kim (2004) carried out an experimental study for a compliant mooring system keeping a floating OWC device. The compliant buoy mooring system consists of four mooring systems, each of which has a buoy connected to horizontal and vertical mooring lines. However, this wave energy device was damaged by mooring line failure during a severe storm. This study has been made to clarify the mechanism of mooring line failure for future improvements in mooring line design.

Based on the guyed tower mooring lines, Ji et al. (2011) proposed a mooring system integrating catenary with taut mooring for deep water platform. In their study, some clump weights were applied to the lower end of the taut lines at fixed intervals, which could form a catenary end, tangent to the seabed. In that way, the anchor points were only subjected to the horizontal forces. They carried out the simulation for a semi-submersible. The results showed that the vessel's offsets and the line's tensions could be greatly reduced when the new mooring system was used. Besides, a catenary shape was formed at the lower end of the line, which lowered the requirement of the anti-uplift capacity of the anchors. It is also demonstrated by Yuan et al. (2011) that this combined mooring system was applicable for a wide range of water depth. But, as pointed by the author, the maximum tension of the new mooring system turned out to be a little larger when the water depth exceeds $1000 \mathrm{~m}$.

In this paper, a new hybrid mooring system with the clump weights and buoys will be proposed. It is based on the combined mooring system proposed by $\mathrm{i}$ et al. (2011). In the present work, some 
improvements are made by attaching some buoys to the previous mooring lines. In this way, the top tension on the lines could be reduced. Meanwhile, this new hybrid system is expected to keep the merits of the previous one since the clump weights are retained.

\section{Description of the new mooring system}

The design of the present hybrid mooring lines is based on the traditional taut mooring lines. It can be seen from Fig. 1 that the mooring lines are connected to the floating structures and go in a fairly straight line to the bottom. This is only possible with light lines, therefore modern polyester lines are needed to achieve this. These lines have a large axial resistance and good fatigue properties. When the platform drifts horizontally with wind or current, the lines stretch and this sets up an opposing force. The lines usually come in at a 30 to 45 degree angle on the seabed where they meet the anchor, which is loaded vertically. Therefore, the suction piles must be used for deep water taut mooring lines to resist the vertical forces. Suction piles can be used in sand, clay and mud soils, but not gravel, as water can flow through the ground during installation, making suction difficult. And also suction piles are usually not allowed to be applied in reefs for the environmental protection. Furthermore, the installation and maintenance of the suction piles is very expensive.

In order to reduce the vertical component of the mooring force at the lower end of the mooring line, a series of clump weights are attached at the lower end of each line, which is shown in Fig. 2. And a couple of these mooring lines with clump weights can constitute a hybrid system, which can be called hybrid mooring system with weights (HMSW). It can be seen from Fig. 2 that the weights are attached to the lines at uniform intervals and the sizes of these weights decrease gradually from the sea bottom upwards. Therefore, the lower end of each line is expected to behavior as a catenary if the weights are arranged properly. When the lines are subjected to the maximum tension, it should be designed to fulfill the following condition: the clump weight ( $m_{1}$ in Fig. 6) next to the anchor point should never be lifted off from the sea floor. Thus, it can be guaranteed that there is no vertical force at the lower end of the mooring line. When the tension decreases, the weights will be supported by the sea floor, thereby lowering the tension at the fairlead. However, in the numerical simulation (Ii et al., 2011), the tensions could be increased by the gravity of the weights. In order to lower the tension on the line, a buoy is attached to each mooring line, shown in Fig. 3. A couple of mooring lines with weights and buoys constitute a new hybrid system, which can be called hybrid mooring system with weights and buoys (HMSWB). The buoyancy of these buoys will counteract some of the gravity, and as a result, the tension on each mooring line can be reduced. The angle between the water line and the mooring line could also be reduced consequently. Thus, the horizontal restoring force provided by the line can be increased while the restoring forces in vertical direction will be reduced. Based on the same principle as the HMSW, the proper arrangement of the weights in HMSWB should also guarantee a horizontal alignment of the mooring line near the sea bed.

In engineering practice, the weights can be made from different materials with various shapes. The typical weights should be steel cubes, which are connected to the mooring chain by shackles. Each mooring line can be assembled onshore or on the board. Tugboats are in charge of towing the lines to the designated points. The buoys are widely used in deep water risers, and the installation technology could be similar. Compared to the suction piles, the manufacturing costs of the weights and buoys could be much lower. The difficulties involved in the installation of the new mooring system are quite different from the taut mooring system. The former rests with the towage of the lines to the designated points, while the latter involves in a suction (relative to seabed water pressure), which is applied within the pile and forces the pile to embed itself, leaving the top flush with the seabed. The scope of 
application of the new hybrid mooring lines can be expanded to a wide range of seabed conditions, including sand, clay and mud soils, but also gravel and reefs. Besides, the new mooring lines are easy to recycle.

\section{Formulations}

The motion equation of the platform is combined with the mooring lines in the time domain as follows:

$$
\left[M+\mu_{\infty}\right] \ddot{x}+\int_{0}^{\infty} R(t-\tau) \dot{x} d \tau+C x=F^{f k}+F^{d}+F^{s d}+F^{w}+F^{c}+F^{m}
$$

In the left hand side of Eq. (1), $M$ is the structure mass, $\mu$ is the infinite added mass, $R(t-T)$ is the retardation function, $C$ is the hydrostatic restoring coefficients. The added mass and radiation damping can be obtained by solving boundary value problem (BVP) and the retardation function can be obtained by inverse cosine Fourier transform of radiation damping. In the right hand side of Eq. (1), $F^{f k}$ is the Froude-Krylov force, $F^{d}$ is the diffraction force, $F^{s d}$ is the second-order wave load, $F^{w}$ is the wind load, $F^{c}$ is the current load, $F^{m}$ is transmitted force from the mooring line. The Froude-Krylov force and diffraction force can be obtained by solving boundary value problem (BVP) in frequency domain with the Fourier transformation. The second-order wave load is calculated by far field integration method in frequency domain with the Fourier transformation. Only horizontal second-order wave forces are calculated in the present study. The wave load is caused by average wind velocity and fluctuating wind velocity. It can be expressed by

$$
F^{w}=C_{w} A_{w} v^{2}
$$

where $C_{w}$ is the wind force coefficient; $A_{w}$ is projected area; $v$ is the wind velocity. The time history of fluctuating wind velocity can be calculated by wind spectrum with Fourier transformation. In the present study, only horizontal wind loads (surge, sway and yaw) are calculated.

All body current forces are computed using the current velocity at the surface $(z=0)$. Traditionally, the viscous surge and sway force and yaw moment have been calculated based on current coefficients and the instantaneous magnitude of the translational relative velocity between the vessel and the fluid. The current drag forces are then expressed by (SIMO, 2009):

$$
\begin{gathered}
F^{c}(\alpha, t)=C_{1}(\alpha)|u|+C_{2}(\alpha)|u|^{2} \\
|u|^{2}=\left(v_{1}-\dot{x}_{1}\right)^{2}+\left(v_{2}-\dot{x}_{2}\right)^{2} \\
\alpha=\arctan \frac{v_{2}-\dot{x}_{2}}{v_{1}-\dot{x}_{1}}
\end{gathered}
$$

where $C_{1}$ and $C_{2}$ are the linear and quadratic current force coefficients respectively; $u$ is the relative velocity between low-frequency body velocity and current velocity; $\alpha$ is the relative angle between direction of low-frequency body velocity and current velocity; $v_{1}$ and $v_{2}$ are the longitudinal and transverse components of current velocity respectively; $\dot{x}_{1}$ and $\dot{x}_{2}$ are the surge and sway velocity respectively. 
The present hybrid mooring lines are composed of four components: chain, polyester line, clump weights and buoys. Since the chain and polyester line are slender structures, the wave forces on these slender lines are calculated by using Morison's equation. The inertia and drag forces are usually computed separately for directions normal and tangential to the line, since the hydrodynamic coefficients in the two directions are different in general. The drag force per unit length is calculated as:

$$
F^{D}=\frac{1}{2} \rho \pi D C_{d t} v_{t}\left|v_{t}\right|+\frac{1}{2} \rho D C_{d n} v_{n}^{2}
$$

where $\rho$ is water density; $D$ is the diameter of the line; $C_{d t}$ is the nondimensional quadratic tangential drag force; $C_{d n}$ is the nondimensional quadratic normal drag force; $v_{t}$ and $v_{n}$ are the tangential and normal flow velocity respectively. The inertia force per unit length is likewise calculated as:

$$
F^{I}=\frac{1}{4} \rho \pi D^{2} C_{m t} \dot{v}_{t}+\frac{1}{4} \rho \pi D^{2} C_{m n} \dot{v}_{n}
$$

where $C_{m t}$ is the nondimensional quadratic tangential inertia force; $C_{m n}$ is the nondimensional quadratic normal inertia force; $\dot{v}_{t}$ and $\dot{v}_{n}$ are the tangential and normal flow acceleration respectively.

The clump weights and buoys are treated as special elements with different mechanical properties. The loads on these elements are determined by their mass, volume and hydrodynamic coefficients. The drag forces acting on a buoy (or clump weight) are calculated according to the following formulae (DeepC, 2010):

$$
\begin{aligned}
& F_{x}^{D}=\frac{1}{2} \rho B_{x} C_{d x} v_{x}\left|v_{x}\right| \\
& F_{y}^{D}=\frac{1}{2} \rho B_{y} C_{d y} v_{y}\left|v_{y}\right| \\
& F_{z}^{D}=\frac{1}{2} \rho B_{z} C_{d z} v_{z}\left|v_{z}\right|
\end{aligned}
$$

where $B_{x}, B_{y}$ and $B_{z}$ are the projected area for flow in $\mathrm{x}, \mathrm{y}$ and $\mathrm{z}$ direction individually; $C_{d x}, C_{d y}$ and $C_{d z}$ are the corresponding nondimensional drag coefficients; $v_{x}, v_{y}$ and $v_{z}$ are the flow velocity in $x, y$ and $z$ direction. The inertia forces acting on a buoy (or clump weight) are likewise calculated as:

$$
\begin{aligned}
& F_{x}^{I}=\rho V C_{a x} \dot{v}_{x} \\
& F_{y}^{I}=\rho V C_{a y} \dot{v}_{y} \\
& F_{z}^{I}=\rho V C_{a z} \dot{v}_{z}
\end{aligned}
$$

where $V$ is the volume of the clump weights (or buoys); $C_{a x}, C_{a y}$ and $C_{a z}$ are the nondimensional inertia coefficients in $x, y$ and $z$ direction; $\dot{v}_{x}, \dot{v}_{y}$ and $\dot{v}_{z}$ are the corresponding flow acceleration in $x, y$ and $z$ direction. 


\section{Numerical study}

\subsection{Description of the platform}

A typical semi-submersible (as shown in Fig. 4) in Gulf of Mexico is simulated to investigate the effectiveness of the proposed hybrid mooring system in different water depths. The horizontal $x-y$ plane of the model is set on the base line with its origin placed on the center of the body, and z-axis is positive upward. The main particulars of the platform are summarized in Table 1. For the loading condition of the analysis, the 100-year extreme hurricane condition at GoM is used, which is one of the severest in the world. The summary of the environmental condition for this study is shown in Table 2 . In the time domain analysis, the simulation duration of time is $600 \mathrm{~s}$ with the time step of $0.2 \mathrm{~s}$. The ramp duration is 10s. Newmark integration procedure is applied with its integration operator $\beta=0.25$ and $\gamma=0.5$. The viscous roll damping fixed at $1500000 \mathrm{kNs} / \mathrm{m}$.

\subsection{Description of the mooring lines}

The semi-submersible platform is moored by three different mooring systems: taut mooring system (TMS), hybrid mooring system with weights (HMSW) and hybrid mooring system with weights and buoys (HMSWB). The latter two systems can be classified as the hybrid mooring system (HMS). The only difference between TMS and HMS should be the weights and buoys as shown in Fig. 1-Fig. 3. Each mooring system is composed of 12 hybrid mooring lines, which is shown in Fig. 5 . Table 3 gives the details of each mooring line. To compensate for the pretension from the risers and mooring lines, a vertical force of magnitude $2233 \mathrm{kN}$ pointing upwards is specified at CG of the platform.

As for the hybrid mooring system, five weights are attached at the lower end of each mooring line with a uniform spacing of $20 \mathrm{~m}$ (Fig. 6). The size of the weights decreases from the bottom upwards, where $m_{1}=20 t, m_{2}=15 t, m_{3}=10 t, m_{4}=5 t, m_{5}=2 t$. The buoys on each mooring line are designed to be sphere, attached $152 \mathrm{~m}$ away from the fairleads. The mass of the buoy is $2 t$. The volume is $18 \mathrm{~m}^{3}$, and $C_{d}=0.5$, $C_{a}=0.1$.

\subsection{Motion responses of the platform}

The time history of sway, heave and roll motions of the platform moored by TMS, HMSW and HMSWB is shown in Fig. 7-Fig. 9. Table 4 gives the statistical variability of the standard deviations, the maximum and mean values of the motion responses. It can be found that the standard deviations of the sway response can be slightly reduced by using HMS (HMSW and HMSWB). The clump weights modify the configuration of the mooring lines. The static equilibrium position will be changed consequently. That is the reason for the large discrepancies of the maximum and mean values between TMS and HMS. For heave and roll motions, the difference of standard deviations between TMS and HMS is not evident. But, it can be observed that in heave motion, the mean value is slightly increased by using HMSW. This is because the clump weights will enlarge the top tension of the lines (as shown in Fig. 13) and the draft of the platform will be increased accordingly. But HMSWB can reduce the mean value of heave motion, since the top tension of the lines can be reduced by the attached buoys. By using fast Fourier Transform (FFT), the motion spectra of the platform can be obtained and plotted in Fig. 10-Fig. 12. The shapes of the spectral are similar and the difference of peak values is very small. The sway, heave and roll motions are dominated by wave frequency (WF) responses. Low frequency (LF) responses can also be observed in sway and roll motions, but it is not significant. 


\subsection{Tension on the mooring lines}

We find that the static tension of Line 10 is the largest of all. Therefore, Line 10 is selected in this paper to investigate the tension results. Fig. 13 is the static tension of Line 10. It can be observed that the static tension keeps a downward trend as the lines extend to the sea bed and the element next to the fairlead is subjected to the largest tension. Comparing with TMS, HMSW could significantly increase the static tension on the mooring lines. But for the system with attached buoys (HMSWB), a very large reduction can be observed at the length ranging from $0 \mathrm{~m}$ to $152 \mathrm{~m}$ (the buoy is attached at $152 \mathrm{~m}$ away from the fairlead). After a sharp increase around $152 \mathrm{~m}$, the static tension of HMSWB exceeds that of TMS and interposes between HMSW and TMS. It can also be found that the static tension changes slowly at the length ranging from $150 \mathrm{~m}$ to $1750 \mathrm{~m}$. This is because the material of the lines at this range is the polyester, which is much lighter than the chain segment at the lower and upper ends of the lines. At the lower end of the line, the last few elements keep a constant tension, which indicates these elements are resting entirely on the sea bed.

Fig. 14 shows the dynamic top tension on Line 10. Table 4 gives the statistical variability of the standard deviations, the maximum and mean values of the tension. It can be found that the standard deviations of the dynamic tension can be reduced by HMS. The clump weights behavior like a buffer, which can reduce the fluctuations of the tension. The buffering effect will be reduced by the attached buoys. It is the reason why the standard deviation of HMSWB is smaller than that of HMSW. But the buoys will reduce the mean and maximum values of the top dynamic tension. Fig. 15 is the tension spectrum results. The shapes of the three spectral are similar, while a very large discrepancy can be observed around the peak values. Consistent with the time history results, TMS has the largest peak value, followed by HMSWB and HMSW sequentially. It can also be observed that the wave frequency tension takes the dominate part.

\subsection{Catenary end}

The configuration of the lines is determined by the altitude value at each node. The position of each clump weight can be represented by its corresponding node. By linking all the nodes on the mooring lines, we can obtain the time series of the line shape. Fig. 16 (a) shows the catenary shapes of three different mooring systems at the moment when Line 10 is subjected to the maximum tension. It can be observed that the catenary shape has been achieved for both HMSW and HMSWB, while the shape of TML is almost a straight line. In order to investigate the difference between HMSW and HMSWB, we enlarge the plot for the last two nodes, which is shown in Fig. 16 (b). The two nodes at $1856 \mathrm{~m}$ and 1876 $m$ of the line correspond to the position of $m_{2}$ and $m_{1}$ respectively, and $1896 \mathrm{~m}$ is anchor point. As for HMSW, there is a slight lift height of $m_{1}$, which indicates the lines are not entirely tangent to the sea bed. But $m_{1}$ is resting on the sea bed entirely for HMSWB. It can be concluded that the buoys can some bring positive effects to form the catenary end. However, the buoys will bring more complexities, difficulties and costs to deepwater installation.

\subsection{The effect of the buoys}

The arrangement of the clump weights was discussed by \i et al. (2011). This study will discuss the effect of the buoys. Line 10 is selected to investigate the line tension.

\section{(1) The effect of the volume of the buoys}


The volume of the buoys will influence the motions of the platform and the tension on the lines. In this paper, we make the optimal study over a wide range of the volumes $\left(\mathrm{V}=7 \mathrm{~m}^{3}, 12 \mathrm{~m}^{3}, 17 \mathrm{~m}^{3}, 22 \mathrm{~m}^{3}, 27 \mathrm{~m}^{3}\right.$, $32 \mathrm{~m}^{3}$ ). The other parameters are kept unchanged.

The displacement in Fig. 17 indicates the offset $\left(D=\sqrt{x^{2}+y^{2}+z^{2}}, x, y\right.$ and $z$ are the motion responses in surge, sway and heave direction) of CG. It can be observed that the displacement changes slowly as the buoy's volume increases from $7 \mathrm{~m}^{3}$ to $22 \mathrm{~m}^{3}$. But a sharp increase of displacement can be observed at the volume ranging from $22 \mathrm{~m}^{3}$ to $32 \mathrm{~m}^{3}$. To the contrary, the maximum tension on the lines keeps a downward trend (as shown in Fig. 18). It drops rapidly as the volume of the buoy increases from $7 \mathrm{~m}^{3}$ to $22 \mathrm{~m}^{3}$. The slope becomes very mild as the volume exceeds $22 \mathrm{~m}^{3}$. Table 6 shows the effect of the volume on the hoisting height of $m_{1}$ and $m_{2}$ when the line is subjected to the maximum tension. As the volume varies from $12 \mathrm{~m}^{3}$ to $22 \mathrm{~m}^{3}$, the hoisting height of $m_{1}$ is 0 , which indicates that $m_{1}$ is entirely resting on the sea bed. While in the other cases, there is a slight elevation of $m_{1}$. The hoisting height of $m_{2}$ experiences a decrease until the buoy volume increases to $17 \mathrm{~m}^{3}$, and then the trend reverses. It can be concluded that the optimal volume should locate among $7 \mathrm{~m}^{3}$ to $22 \mathrm{~m}^{3}$ in the present study.

\section{(2) The effect of the buoy position}

In order to explore the effect of the buoy's position on the floating system, we make the parametric study over a range of distances $(d=30 \mathrm{~m}, 60 \mathrm{~m}, 90 \mathrm{~m}, 120 \mathrm{~m}, 152 \mathrm{~m}$; where $d$ is the distance between the fairlead and the buoy). The volume of the buoys is fixed at $18 \mathrm{~m}^{3}$. Meanwhile, all the other parameters keep unchanged.

The displacement in Table 7 indicates that there is only a very slight decrease of the displacement as the distance increases from $30 \mathrm{~m}$ to $152 \mathrm{~m}$. But the static tension on the lines will be greatly influenced by the distance, as shown in Fig. 19. As the distance increases, the maximum static tension can be reduced accordingly. The maximum static tension can be found at the node corresponding to the buoys as the distance is smaller than $90 \mathrm{~m}$. When the distance is greater than $90 \mathrm{~m}$, the static tension at the fairlead becomes the largest one. An optimal design should guarantee that the distribution of the tension on the line is as equivalent as possible. Based on this principle, the distance in the present case study should be greater than $90 \mathrm{~m}$. Consistent with the static tension results, the maximum dynamic tension also keep a downward trend as the as the distance increases from $30 \mathrm{~m}$ to $152 \mathrm{~m}$, which can be observed from Fig. 20. Table 8 gives the hoisting height of $m_{1}$ and $m_{2}$ at different distance. We find $m_{1}$ is resting on the sea bed for all the distances we adopted in the present case study. However, the hoisting height of $m_{2}$ keeps a downward trend as the distance increases from $30 \mathrm{~m}$ to $152 \mathrm{~m}$.

\subsection{The effect of the water depths}

In order to explore the application range of the proposed hybrid system, we make the comparison over a range of water depths $(h=500 \mathrm{~m}, 750 \mathrm{~m}, 1000 \mathrm{~m}, 1500 \mathrm{~m}, 2000 \mathrm{~m}, 3000 \mathrm{~m}$; where $h$ is the water depth). All the parameters keep unchanged except the water depth and the line length shown in Table 9.

\section{(1) Displacement of the platform}

The statistical variability of the displacement is shown in Table 10 and Fig. 21. Overall, the trend of the displacement is upward as the water depth increases from $500 \mathrm{~m}$ to $3000 \mathrm{~m}$. It can be found that the mean values of the displacement can be reduced by using the present HMS. But the difference between 
HMSW and HMSWB is very small. The difference of the standard deviations is not evident between these three mooring systems.

\section{(2) Tension on the lines}

From Fig. 22 (a), it can be seen that the tension on the lines keeps a downward trend for all the three types of mooring system as the water depth increases from $500 \mathrm{~m}$ to $3000 \mathrm{~m}$. It can be illustrated that the fluctuation of the line tension tends to be mild in deep water. It is also observed that the standard deviations of the tension of the hybrid mooring system (HMS, including both HMSW and HMSWB) is smaller than that of TMS, especially when the water depth is small. The standard deviation of HMSWB is slightly larger than that of HMSW due to the influence from the buoys.

The mean tension on the lines keeps an upward trend, as shown in Fig. 22 (b). Compared with TMS, the mean tension of HMSW tends to be larger due to the gravity of the weights. However, when the buoys are used, the mean tension of HMSWB can be even smaller than that of TMS. The buoyancy pointing upwards from the buoys can lower the tension on the upper ends of the mooring lines, which can also be observed from Fig. 13.

The comparison results of the maximum tension in Fig. 22 (c) are quite similar to the mean tension results at the water depth ranging from $1000 \mathrm{~m}$ to $3000 \mathrm{~m}$. At $500 \mathrm{~m}$ water depth, the maximum tension of TMS tends to be the largest of all. It drops rapidly from $2140 \mathrm{kN}$ to $1750 \mathrm{kN}$ when the water depth increases from $500 \mathrm{~m}$ to $1000 \mathrm{~m}$. But the changes of maximum tension of HMS are not significant at the water depth ranging from $500 \mathrm{~m}$ to $1000 \mathrm{~m}$.

\section{(3) Catenary end}

Fig. 23 shows the catenary ends at different water depths. It can be found that at all water depths, a catenary shape can be formed by using the new hybrid mooring system. But, as it extends to the deep water, the lower ends are more likely to form a catenary shape.

\section{Summary and conclusion}

A new hybrid mooring system with clump weights and buoys was proposed in this paper. The validation was carried out based on the time domian coupled analysis method. Through the comparison between HMS and TMS, the following conclusions can be drawn:

1. The present hybrid mooring system could reduce the displacement of the platform. But the reduction is not evident.

2. The attached buoys could reduce the tension on the mooring lines. This is a significant improment for the mooring system since it provides a good approach to solve the contradiction between the vessel's motion and the line's tension.

3. The catenary end could be formed through an optimal arrangement of the weights and buoys. There was only horizontal component of the loads at the anchor point. As the water depth increses, the mooring lines were more likely to rest on the sea bed and form a catenary shape.

4. The volume and position of the buoys could bring a significant influence to the line's tension. But the influence on the vessel's motion and catenary end is not evident. 
5. The present hybrid mooring system has a wide range of the application. At water depth ranging from $500 \mathrm{~m}$ to $3000 \mathrm{~m}$, it provides a satisfied performance.

Overall, the numerical results indicate that the present hybrid mooring system with clump weights and buoys will bring improvement to the vessel's offsets and the line's tension. It can form a catenary shape at the lower end of the lines, which guarantees that there is only horizontal component of the loads at the anchor point. However, the buoys will bring more complexities, difficulties and costs to deepwater installation. Further replenishment will focus on the experimental study, which will be carried out in the future work.

\section{Acknowledgements}

This study was supported by the National Natural Science and Foundation of China (Grant No. 51379095).

\section{References}

DeepC, 2011. DeepC User Manual. Version 4.5-05.

Finn, L.D., 1976. A new deepwater offshore platform- the guyed tower. In: Offshore Technology Conference, Houston, Texas.

Hong, S.W., Kim, J. H., 2004. Experimental Study of a Compliant Mooring System for a Floating OWC Device, Proceeding of The Fourteenth International Offshore and Polar Engineering Conference, Toulon, France.

Ji, C.Y., Yuan, Z.M., Chen, M.L., 2011. Study on a new mooring system integrating catenary with taut mooring. China Ocean Engineering, 25(3), 427-440.

Johanning, L., Smith, G.H., Wolfram, J., 2007. Measurements of static and dynamic mooring line damping and their importance for floating WEC devices. Ocean Engineering, 34:14-15, 1918-1934.

MARINTEK, 2009. SIMO Theory Manual. Version 3.6.

Morrison, D.G., Asce, A.M., 1983. Guyed tower with dynamic mooring properties. Journal of Structural Engineering 109, 2578-2590.

Smith, R. J., MacFarlane, C. J., 2001. Statics of a three component mooring line. Ocean Engineering 28, pp.899-914.

Vicente, P.C., Falcão, A.F., Justino P. J., 2011. Slack-chain mooring configuration analysis of a floating wave energy converter. 26th International Workshop on Water Waves and Floating Bodies, Athens, Greece.

Yuan, Z.M., Ji, C.Y., Chen, M.L., Zhang, Y., 2011. Coupled analysis of floating structures with a new mooring system. 30th International Conference on Ocean, Offshore and Arctic Engineering, , Rotterdam, The Netherlands. 


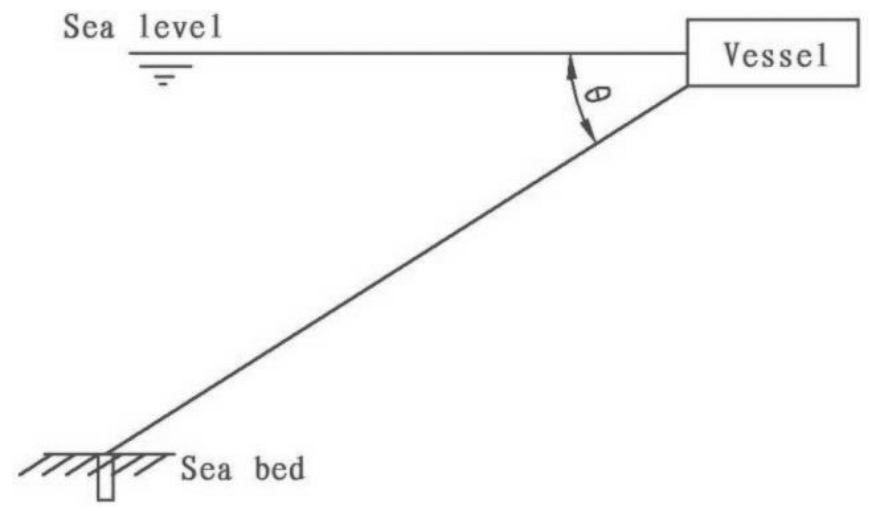

Fig. 1 Taut mooring line (TML)

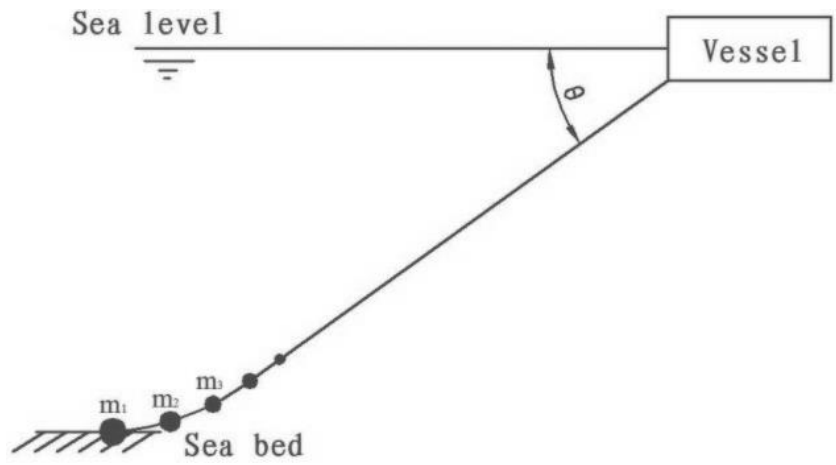

Fig. 2 Hybrid mooring line with clump weights (HMLW)

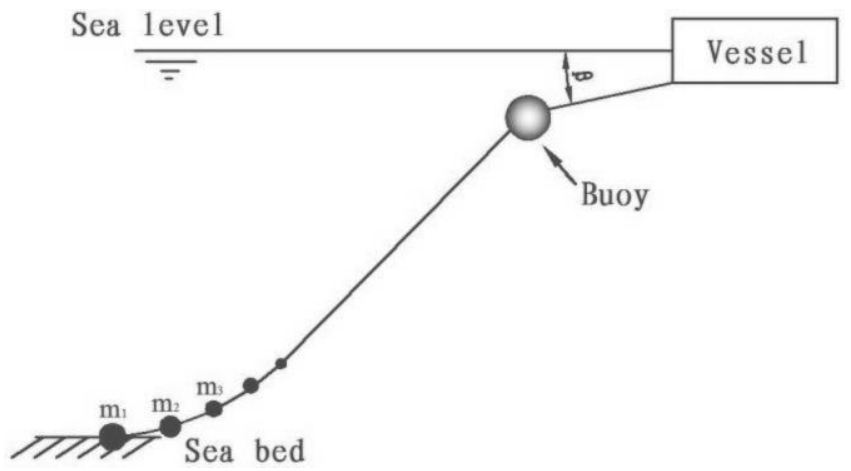

Fig. 3 Hybrid mooring line with clump weights and buoys (HMLWB) 


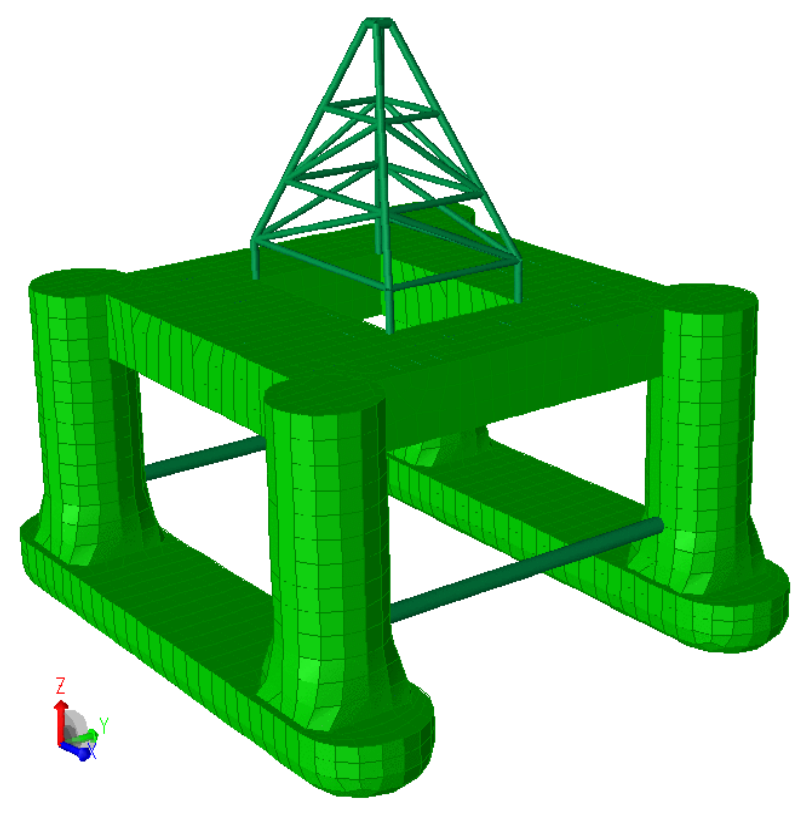

Fig. 4 Semi-submersible platform model

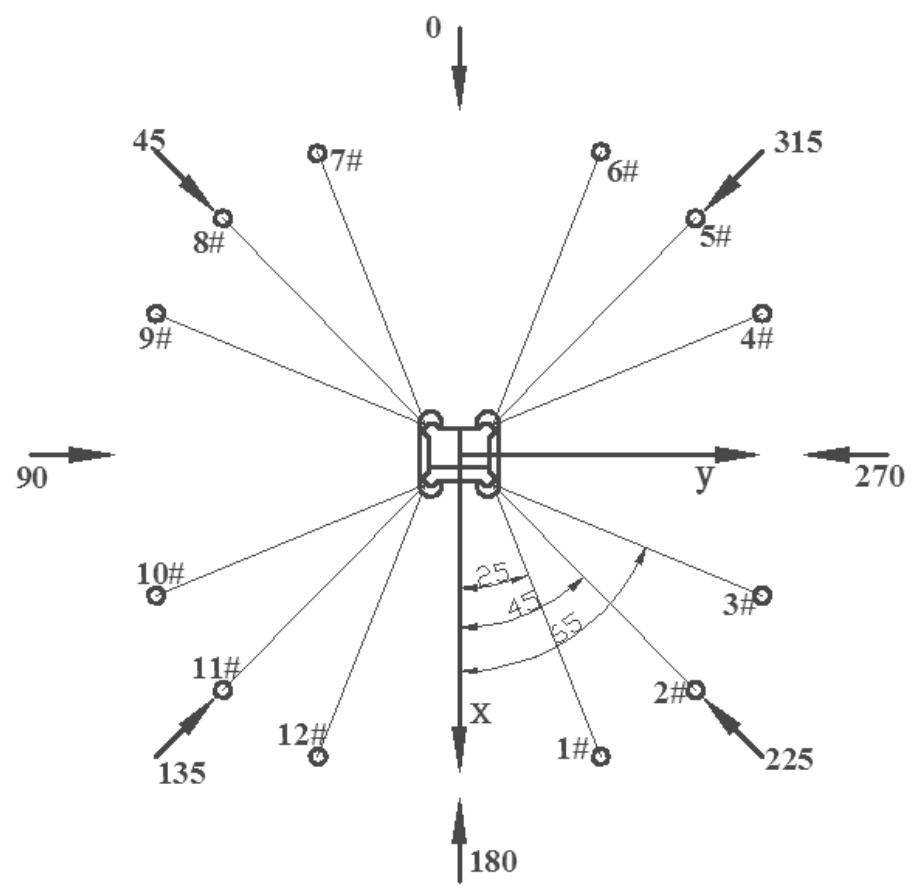

Fig. 5 The arrangement of the mooring lines 


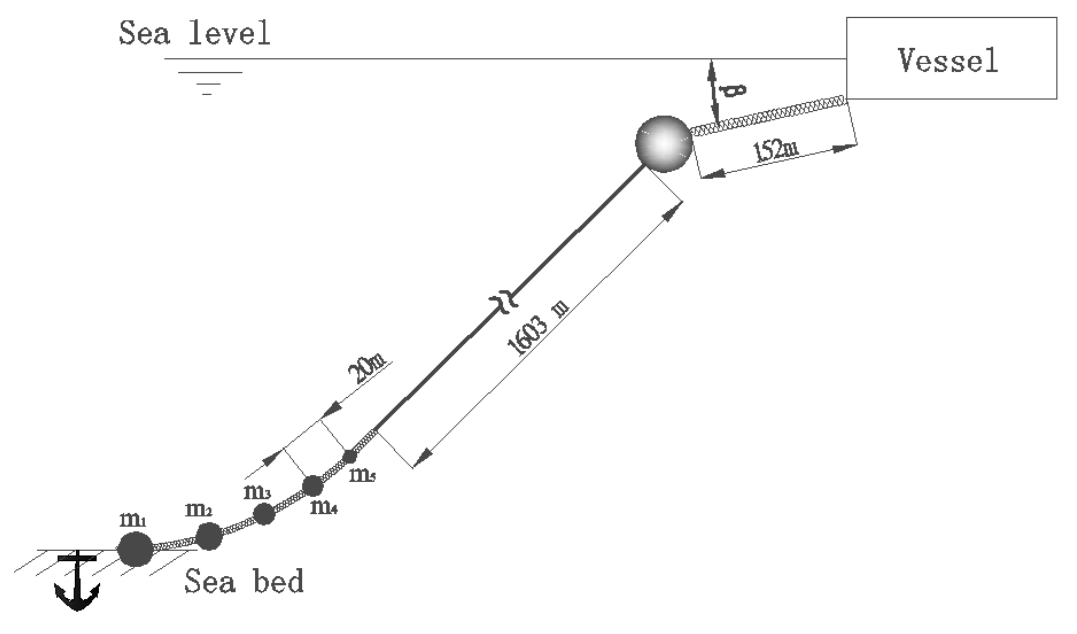

Fig. 6 Hybrid mooring lines

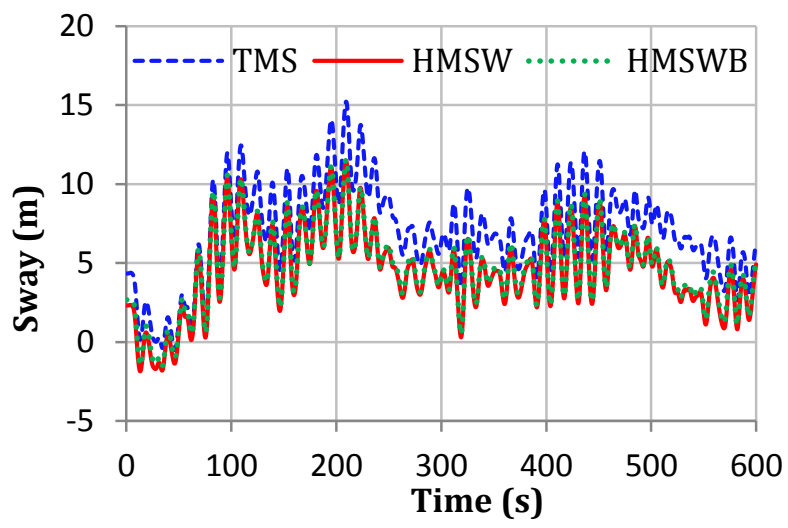

Fig. 7 Time history of sway

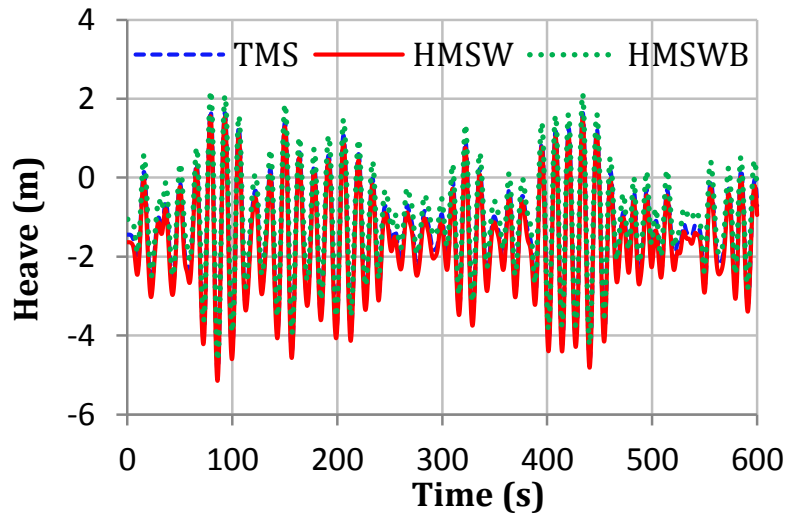

Fig. 8 Time history of heave 


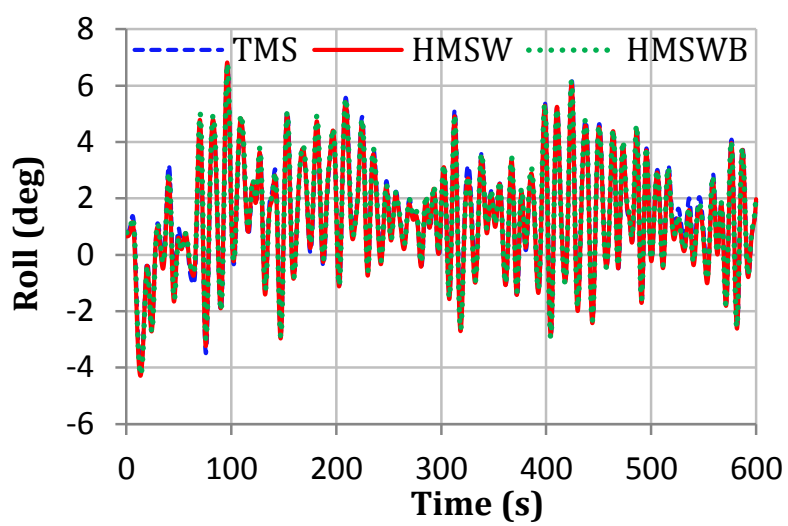

Fig. 9 Time history of roll

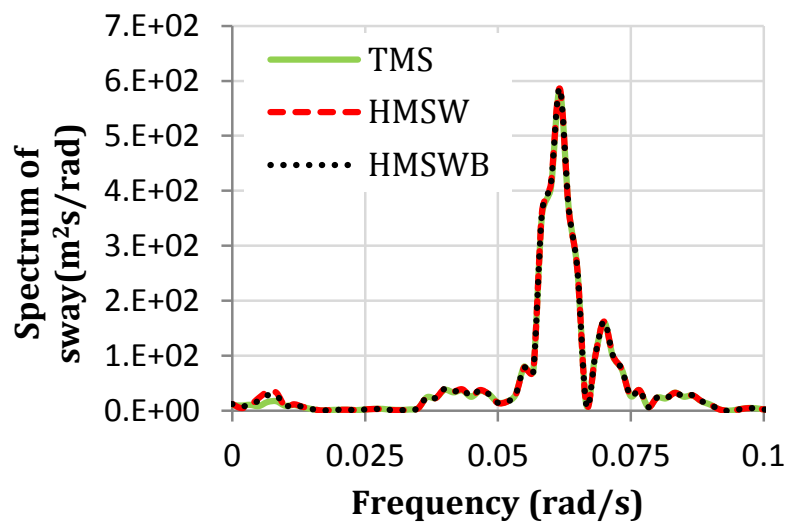

Fig. 10 Spectral density of sway

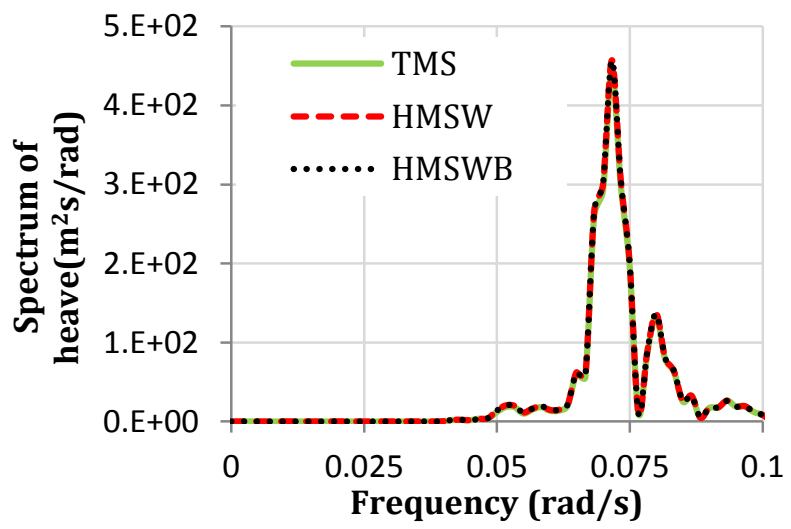

Fig. 11 Spectral density of heave 


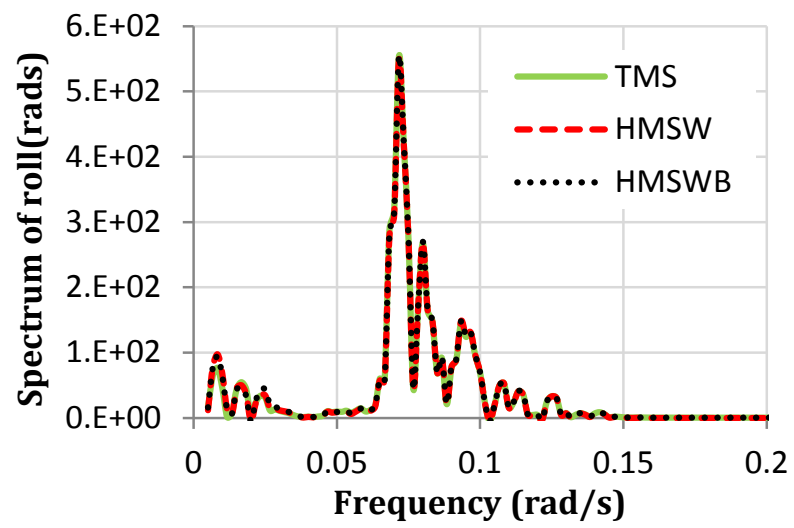

Fig. 12 Spectral density of roll

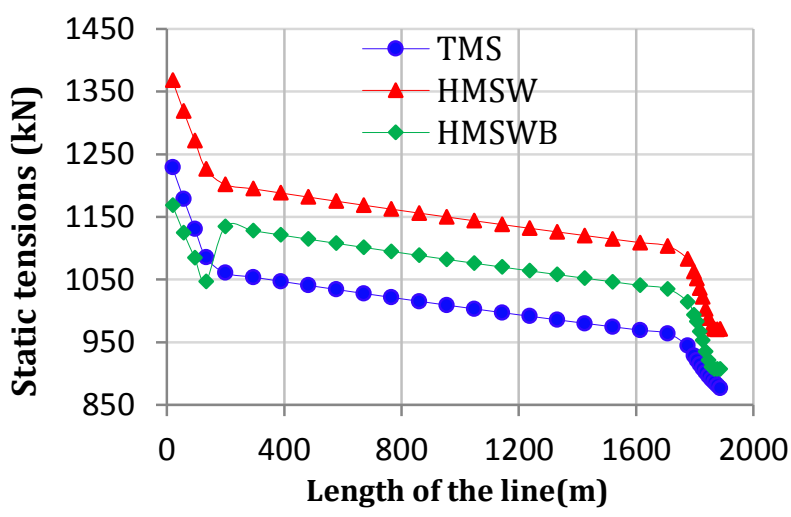

Fig. 13 Static tension

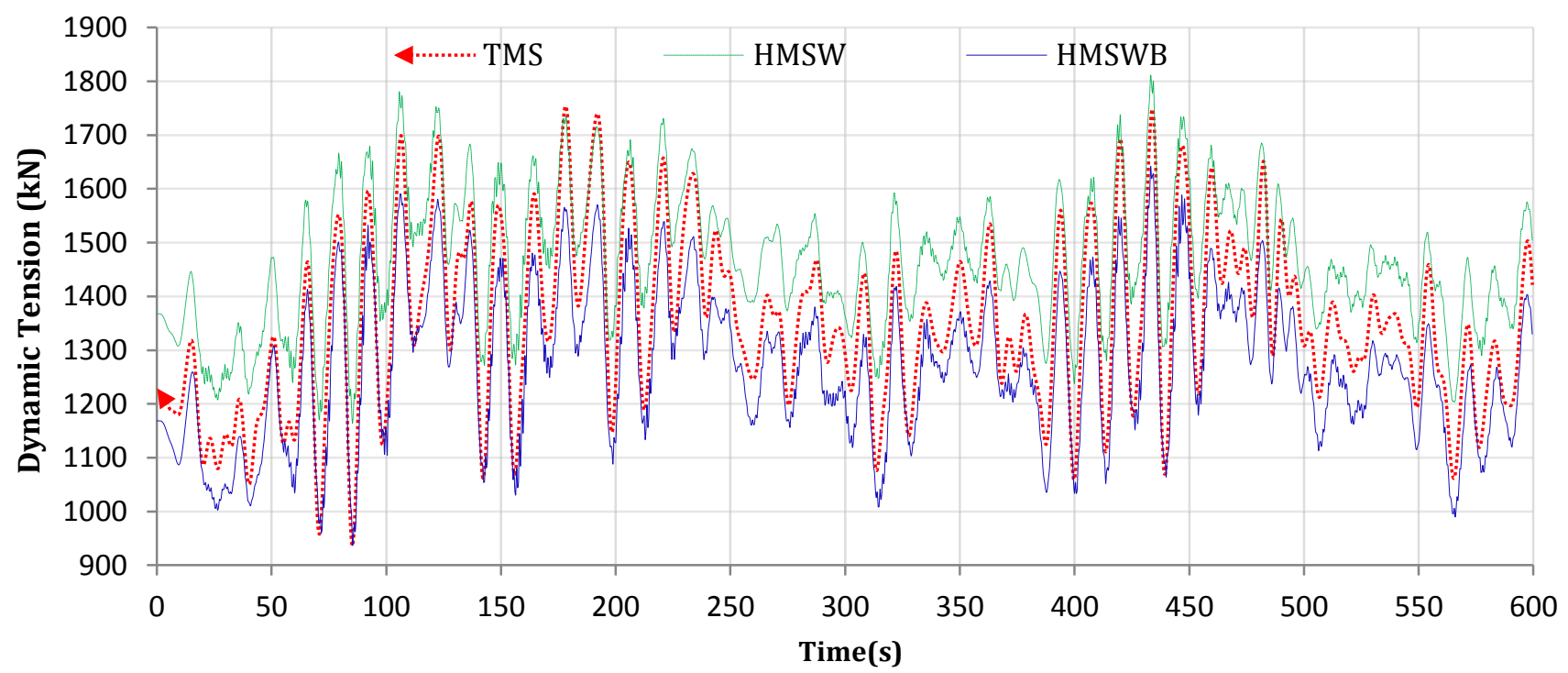

Fig. 14 Dynamic top tension 


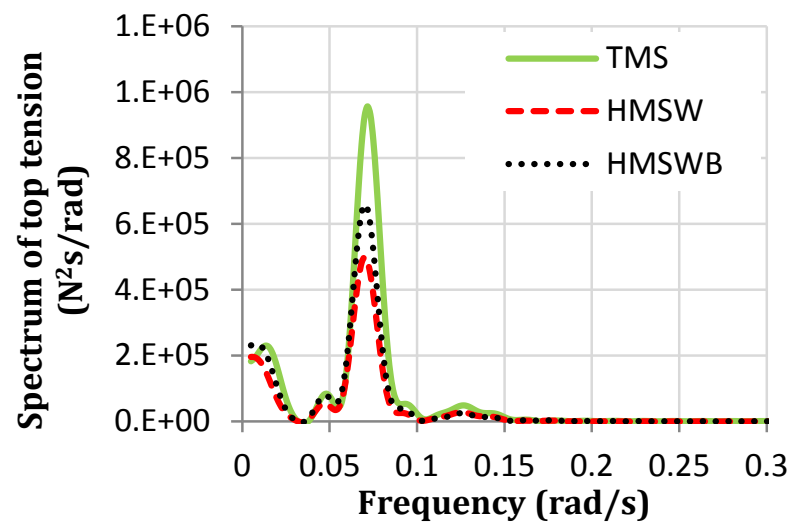

Fig. 15 Tension spectra

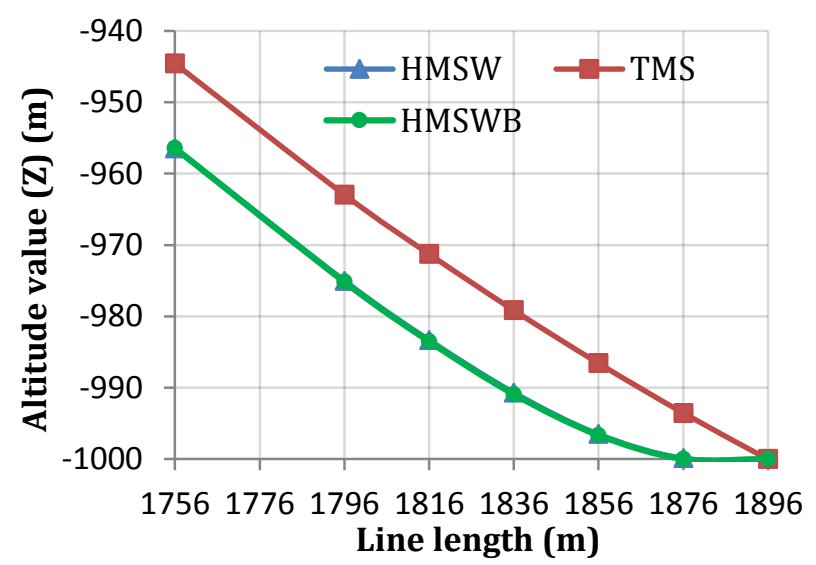

(a)

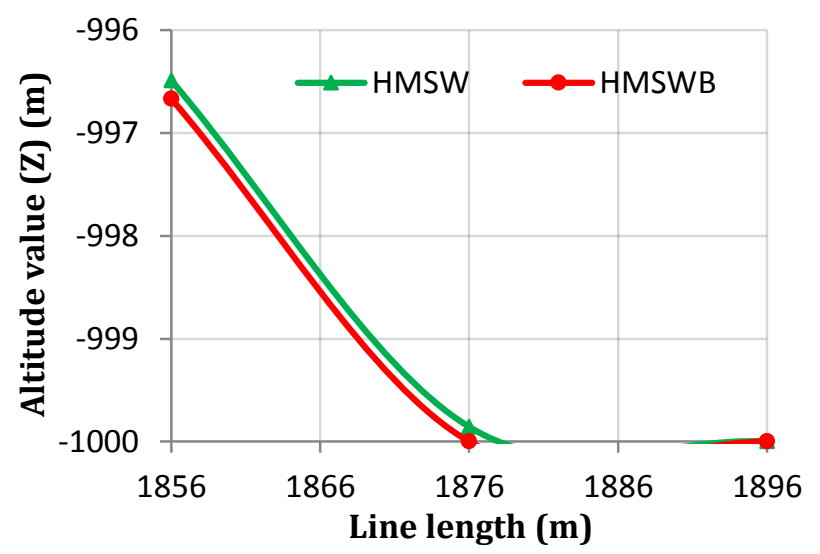

(b)

Fig. 16 Catenary end 


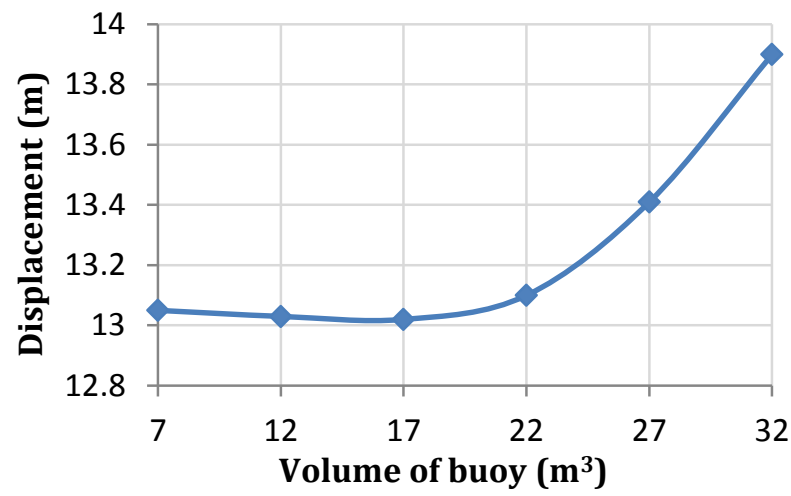

Fig. 17 The displacement of the platform

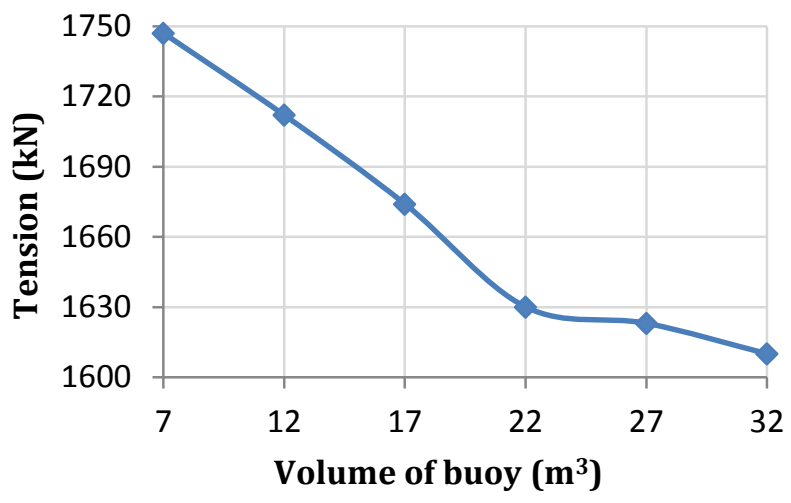

Fig. 18 Tension on the lines

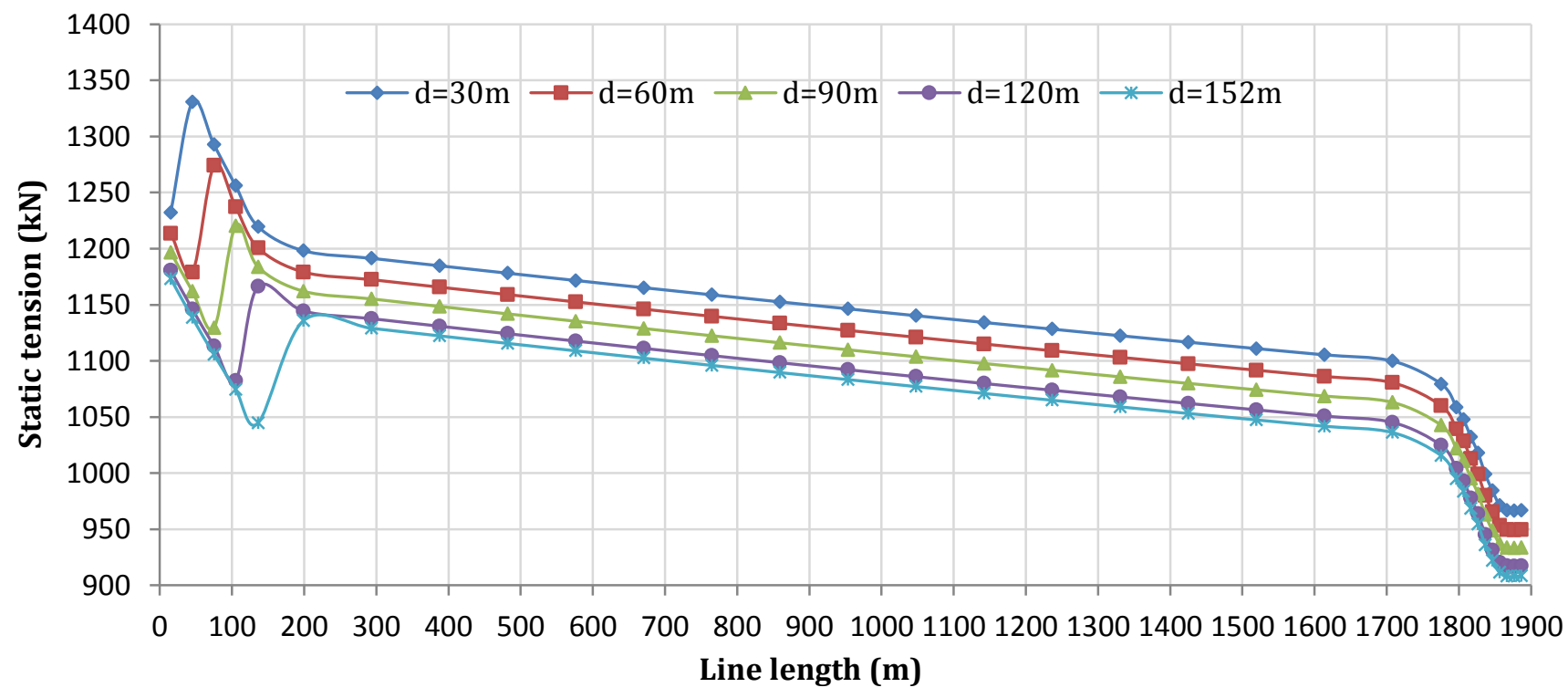

Fig. 19 Static tension at different distances 


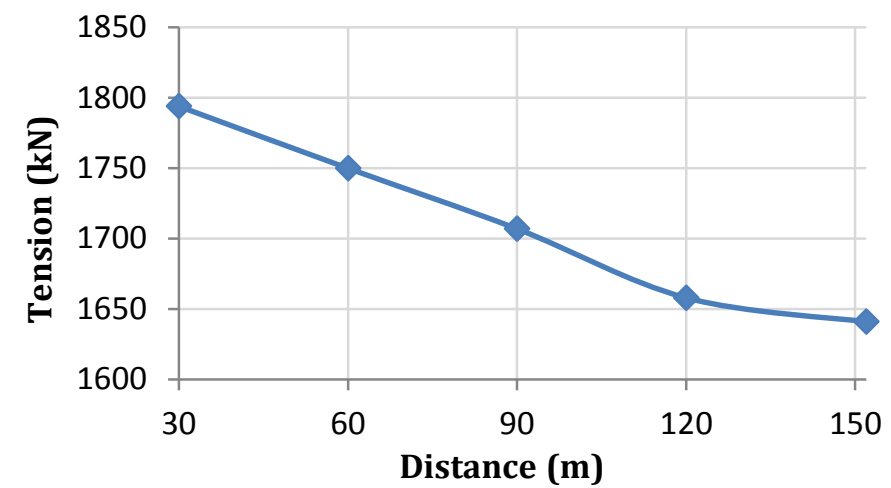

Fig. 20 The maximum dynamic tension of different distances

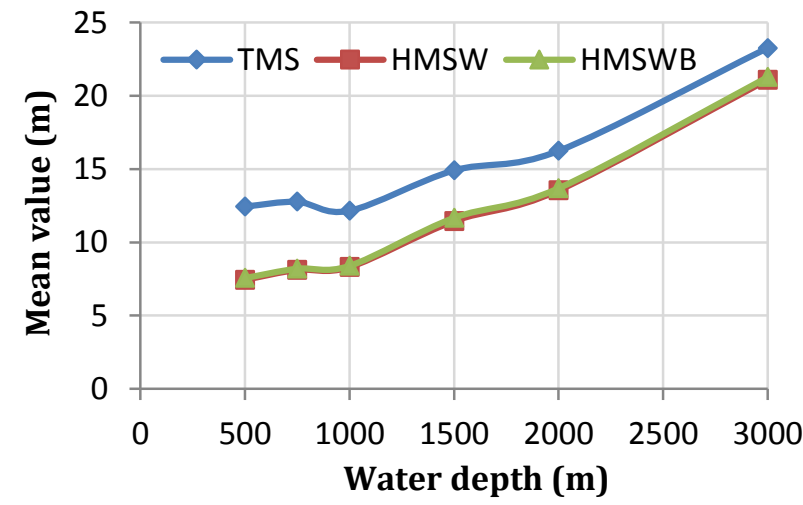

(a)

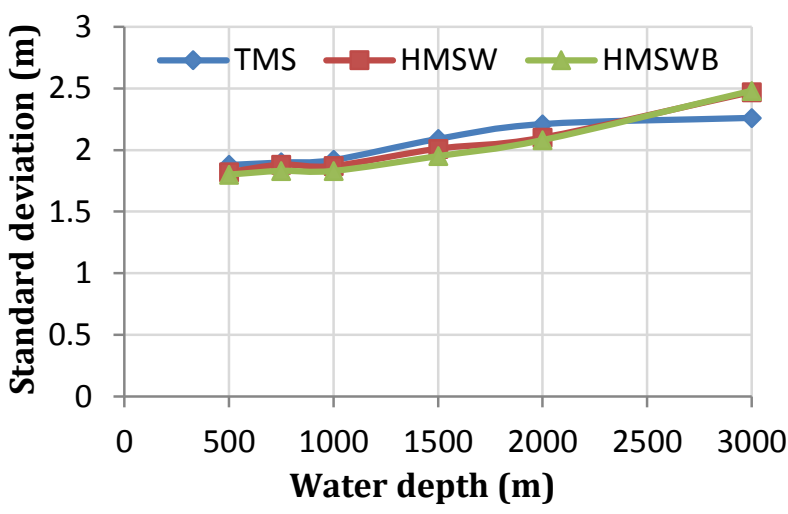

(b)

Fig. 21 The displacement at different water depths. (a) Mean values; (b) Standard deviations. 


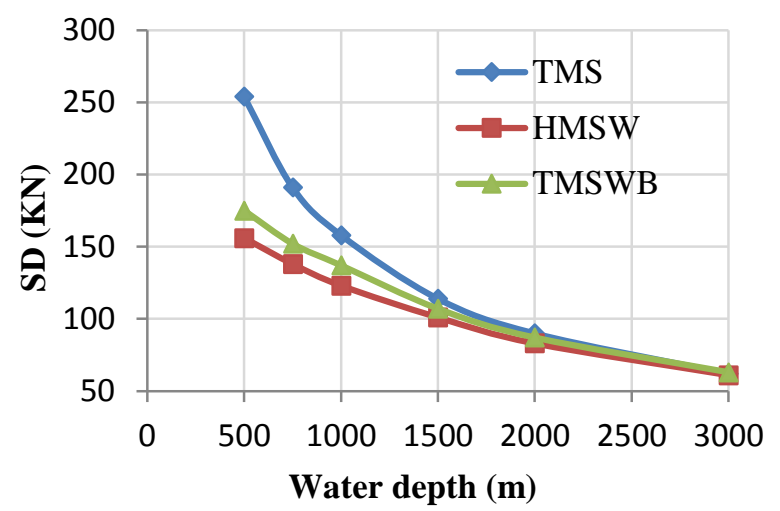

(a)

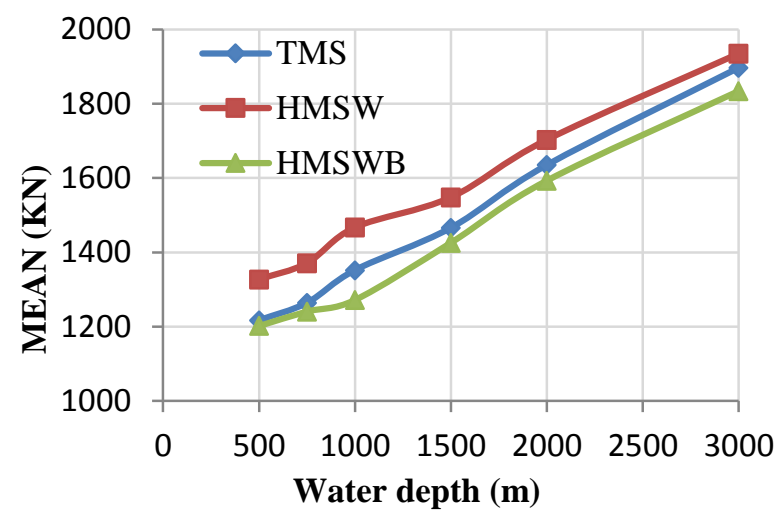

(b)

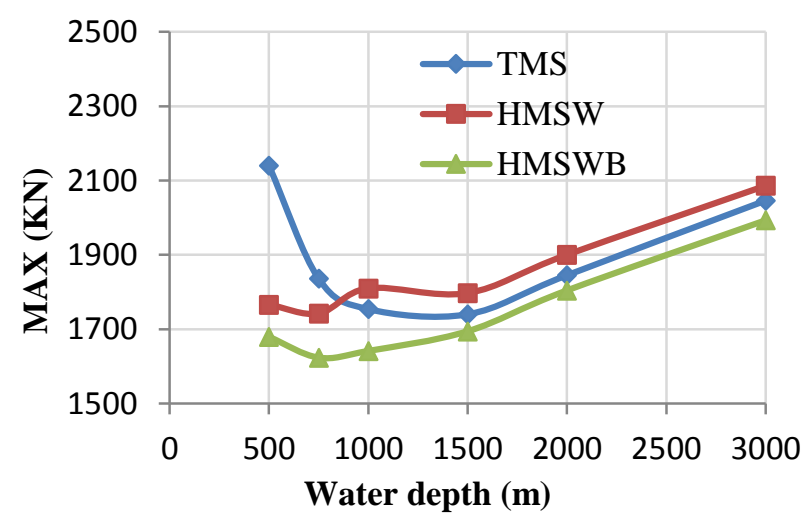

(c)

Fig. 22 Tension on the lines at different water depths. (a) Standard deviations; (b) Mean tension; (c) Maximum tension. 


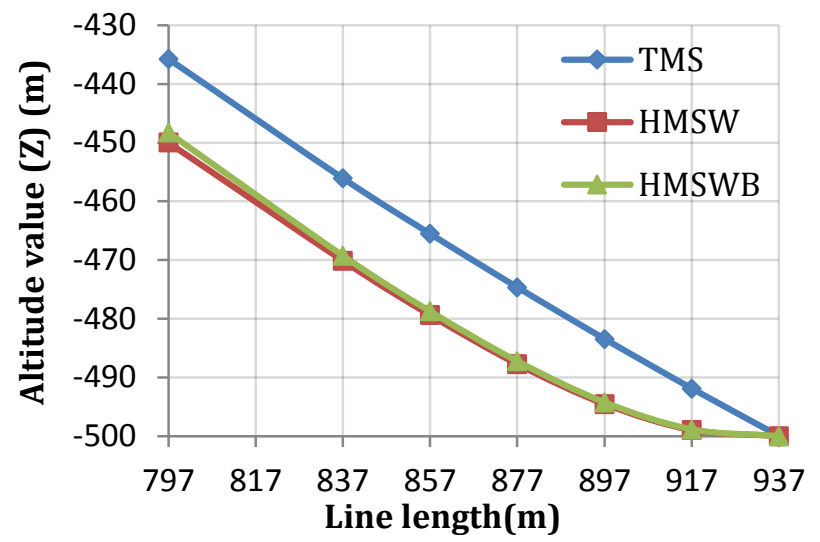

(a)

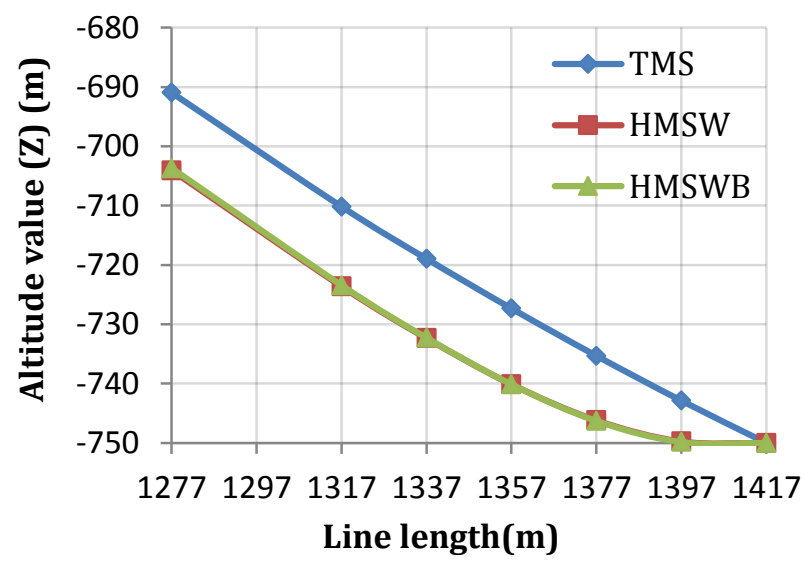

(b)

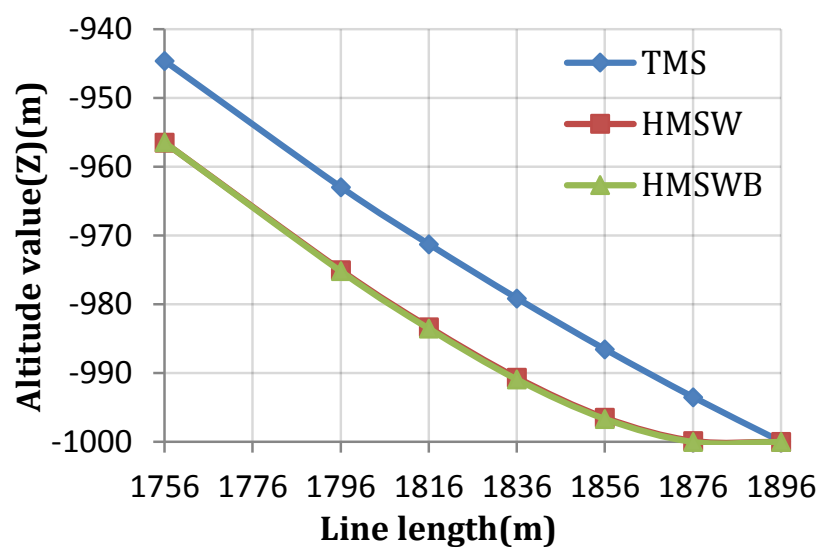

(c) 


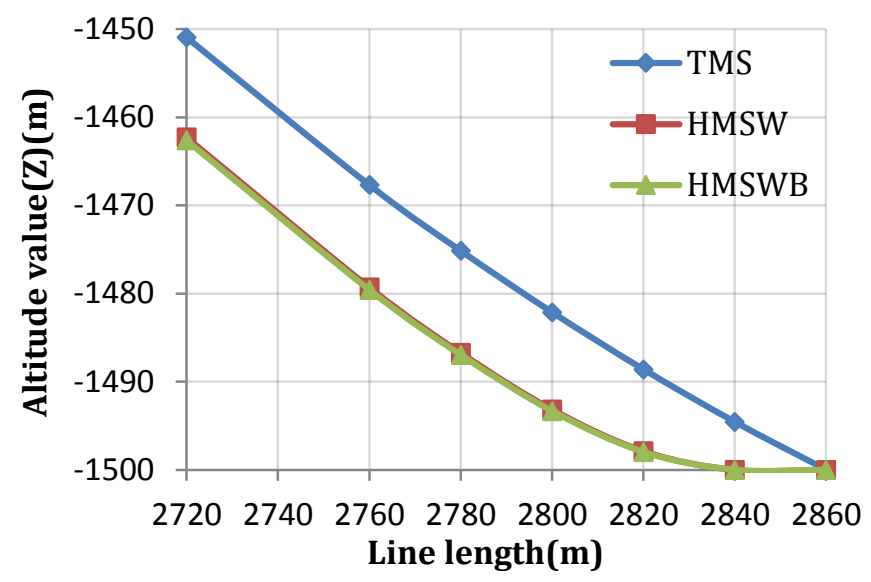

(d)

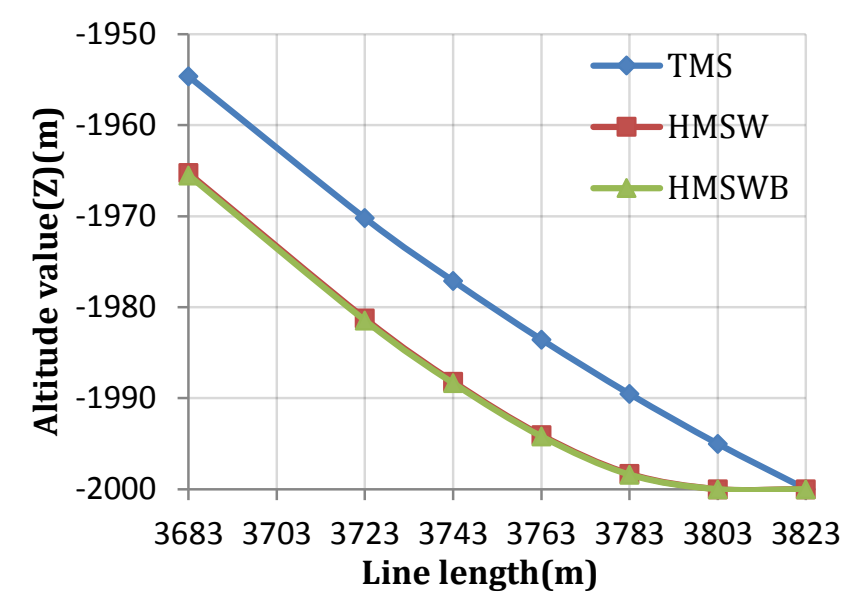

(e)

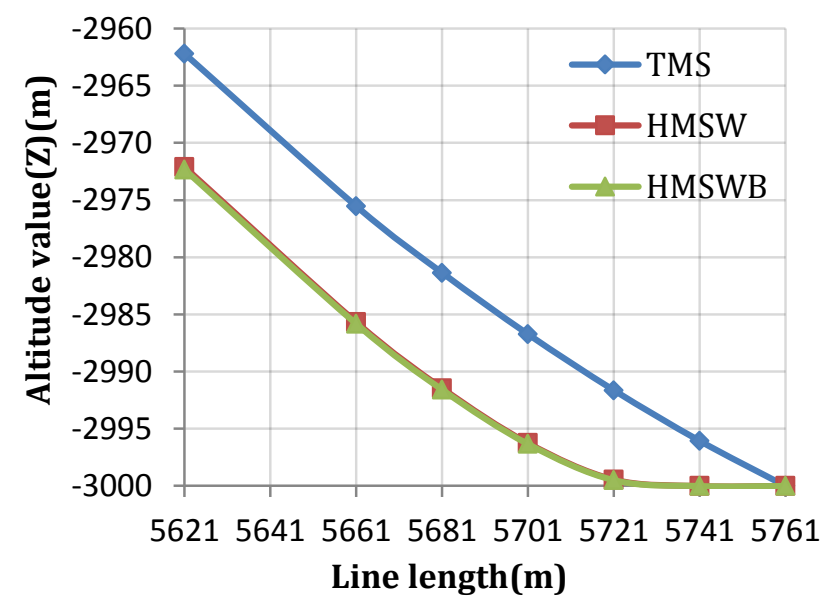

(f)

Fig. 23 The catenary ends at different water depths. (a) 500 m; (b) 750 m; (c) 1000 m; (d) 1500 m; (e) 2000 m; (f) $3000 \mathrm{~m}$. 
Table 1 Main particulars of the platform

\begin{tabular}{lc}
\hline Length $(m)$ & 80.6 \\
Breadth of pontoon $(m)$ & 16 \\
Height of pontoon $(m)$ & 7.5 \\
Diameter of columns $(m)$ & 12.9 \\
Spacing of columns $(m)$ (centre to centre) & 54.72 \\
Displacement $\left(m^{3}\right)$ & 23548 \\
Distance between pontoons $(m)$ & 1.17 \\
Vertical position of CG (above BL) $(m)$ & 14.9 \\
Longitudinal coordinate of CG (forward midship) $(m)$ & 0 \\
Radius of inertia for pitch $(m)$ & 30 \\
Coordinate of Fairlead $1(m)$ & $(33.6,29.0,0)$ \\
Coordinate of Fairlead $2(m)$ & $(31.9,32.9,0)$ \\
Coordinate of Fairlead 3 $(m)$ & $(29.0,33.6,0)$ \\
\hline
\end{tabular}

$\mathrm{CG}$, centre of gravity; BL, base line

Table 2 Environmental loading condition

\begin{tabular}{lr}
\hline Wave & \\
Wave spectrum & JONSWAP \\
Significant wave height $(\mathrm{m})$ & 12.19 \\
Peak period $(\mathrm{s})$ & 14 \\
Direction $(\mathrm{deg})$ & 90 \\
Wind & \\
Wind spectrum & 41.12 \\
Velocity $(\mathrm{m} / \mathrm{s})$ & 60 \\
Direction $(\mathrm{deg})$ & \\
Current & 1.0668 \\
at free surface $(0 \mathrm{~m})(\mathrm{m} / \mathrm{s})$ & 1.0668 \\
at $60.96 \mathrm{~m}(\mathrm{~m} / \mathrm{s})$ & 0.0914 \\
at $91.44 \mathrm{~m}(\mathrm{~m} / \mathrm{s})$ & 0.0914 \\
on the sea bottom $(\mathrm{m} / \mathrm{s})$ & 120 \\
Direction $(\mathrm{deg})$ & \\
\hline
\end{tabular}

Table 3 Main particulars of the mooring lines

\begin{tabular}{cccccccc}
\hline Segment & $\begin{array}{c}\text { Length } \\
(m)\end{array}$ & $\begin{array}{c}\text { Diameter } \\
(m)\end{array}$ & $\begin{array}{c}\text { Wet Weight } \\
(t / m)\end{array}$ & $\mathrm{EA}(M N)$ & $\mathrm{C}_{d n} / C_{d t}$ & $C_{m n} / C_{m t}$ & $\begin{array}{c}\mathrm{MBL} \\
(k N)\end{array}$ \\
\hline Chain & 152 & 0.098 & 0.192 & 802 & $2.45 / 0.65$ & $2 / 0.5$ & 8927 \\
Polyester & 1603 & 0.178 & 0.007 & 300 & $1.2 / 0.3$ & $1.15 / 0.2$ & 9786 \\
Chain & 141 & 0.098 & 0.192 & 802 & $2.45 / 0.65$ & $2 / 0.5$ & 8927 \\
\hline
\end{tabular}


Table 4 Statistical variability of the motions

\begin{tabular}{ccccc}
\hline Motion & Statistical variability & TMS & HMSW & HMSWB \\
\hline \multirow{3}{*}{ Sway $(m)$} & MAX & 15.21 & 11.48 & 11.57 \\
& Mean & 6.92 & 4.53 & 4.75 \\
& SD & 2.98 & 2.62 & 2.55 \\
\hline \multirow{3}{*}{ Heave $(m)$} & MAX & -4.92 & -5.15 & -4.62 \\
& Mean & -1.47 & -1.64 & -1.07 \\
& SD & 1.25 & 1.27 & 1.27 \\
\hline \multirow{3}{*}{ Roll $($ deg $)$} & MAX & 6.74 & 6.82 & 6.76 \\
& Mean & 1.36 & 1.28 & 1.37 \\
& SD & 1.86 & 1.88 & 1.89 \\
\hline
\end{tabular}

MAX: maximum value; SD: standard deviations

Table 5 Statistical variability of tension (unit: $k N$ )

\begin{tabular}{cccc}
\hline & Mean & SD & Max \\
TMS & 1355 & 158 & 1753 \\
HMSW & 1469 & 123 & 1810 \\
HMSWB & 1274 & 137 & 1641 \\
\hline
\end{tabular}

Table 6 The hoisting height of $m_{1}$ and $m_{2}$

\begin{tabular}{ccc}
\hline $\begin{array}{c}\text { Volume } \\
\left(\mathrm{m}^{3}\right)\end{array}$ & $\begin{array}{c}\text { Hoisting height of } \\
m_{1}(\mathrm{~m})\end{array}$ & $\begin{array}{c}\text { Hoisting height of } \\
m_{2}(\mathrm{~m})\end{array}$ \\
\hline 7 & 0.02 & 3.34 \\
12 & 0 & 3.31 \\
17 & 0 & 3.3 \\
22 & 0 & 3.33 \\
27 & 0.01 & 3.46 \\
32 & 0.02 & 3.81 \\
\hline
\end{tabular}

Table 7 Displacement (unit: $m$ )

\begin{tabular}{cccccc}
\hline $\mathrm{d}$ & 30 & 60 & 90 & 120 & 152 \\
\hline Disp. & 13.34 & 13.33 & 13.32 & 13.18 & 13.10 \\
\hline
\end{tabular}

Table 8 The hoisting height of $m_{1}$ and $m_{2}$

\begin{tabular}{cccccc}
\hline Volume $\left(\mathrm{m}^{3}\right)$ & 30 & 60 & 90 & 120 & 152 \\
\hline Hoisting height of $m_{1}(\mathrm{~m})$ & 0 & 0 & 0 & 0 & 0 \\
Hoisting height of $m_{2}(\mathrm{~m})$ & 3.33 & 3.26 & 3.23 & 3.17 & 3.12 \\
\hline
\end{tabular}

Table 9 The length of the mooring lines at different water depths (unit: $m$ )

\begin{tabular}{ccccccc}
\hline Water depth & 500 & 750 & 1000 & 1500 & 2000 & 3000 \\
\hline Upper Chain & 152 & 152 & 152 & 152 & 152 & 152 \\
Polyester Line & 644 & 1124 & 1603 & 2567 & 3530 & 5468 \\
Lower Chain & 141 & 141 & 141 & 141 & 141 & 141 \\
Total Length & 937 & 1417 & 1896 & 2860 & 3823 & 5761 \\
\hline
\end{tabular}


Table 10 The displacement of the platform at different water depths (unit: $m$ )

\begin{tabular}{cccccccccc}
\hline \multirow{2}{*}{$\begin{array}{c}\text { Water } \\
\text { depth }\end{array}$} & \multicolumn{3}{c}{ TMS } & \multicolumn{3}{c}{ HMSW } & \multicolumn{3}{c}{ HMSWB } \\
\cline { 2 - 10 } & Mean & SD & Max & Mean & SD & Max & Mean & SD & Max \\
\hline 500 & 12.45 & 1.88 & 17.56 & 7.44 & 1.82 & 12.12 & 7.56 & 1.80 & 12.27 \\
750 & 12.77 & 1.90 & 17.82 & 8.11 & 1.88 & 12.94 & 8.20 & 1.83 & 12.96 \\
1000 & 12.16 & 1.92 & 17.22 & 8.30 & 1.87 & 13.17 & 8.39 & 1.83 & 13.10 \\
1500 & 14.91 & 2.09 & 20.24 & 11.44 & 2.01 & 16.80 & 11.67 & 1.95 & 16.86 \\
2000 & 16.24 & 2.21 & 21.79 & 13.54 & 2.10 & 18.99 & 13.69 & 2.08 & 19.07 \\
3000 & 23.25 & 2.26 & 29.57 & 21.09 & 2.47 & 27.18 & 21.28 & 2.48 & 27.32 \\
\hline
\end{tabular}

Table 11 Tension on the lines at different water depths

\begin{tabular}{|c|c|c|c|c|c|c|c|c|c|}
\hline \multirow{2}{*}{$\begin{array}{l}\text { Water } \\
\text { depth } \\
(m)\end{array}$} & \multicolumn{3}{|c|}{ TMS } & \multicolumn{3}{|c|}{ HMSW } & \multicolumn{3}{|c|}{ HMSWB } \\
\hline & $\begin{array}{c}\text { Mean } \\
(k N)\end{array}$ & $\begin{array}{l}\mathrm{SD} \\
(k N)\end{array}$ & $\begin{array}{l}\operatorname{Max} \\
(k N)\end{array}$ & $\begin{array}{c}\text { Mean } \\
(k N)\end{array}$ & $\begin{array}{l}\mathrm{SD} \\
(k N)\end{array}$ & $\begin{array}{l}\operatorname{Max} \\
(k N)\end{array}$ & $\begin{array}{c}\text { Mean } \\
(k N)\end{array}$ & $\begin{array}{l}\mathrm{SD} \\
(k N)\end{array}$ & $\begin{array}{l}\operatorname{Max} \\
(k N)\end{array}$ \\
\hline 500 & 1217 & 254 & 2140 & 1327 & 156 & 1766 & 1202 & 175 & 1679 \\
\hline 750 & 1264 & 191 & 1836 & 1371 & 138 & 1742 & 1241 & 152 & 1623 \\
\hline 1000 & 1352 & 158 & 1754 & 1467 & 123 & 1810 & 1272 & 137 & 1641 \\
\hline 1500 & 1466 & 114 & 1740 & 1548 & 101 & 1797 & 1426 & 107 & 1694 \\
\hline 2000 & 1635 & 90 & 1845 & 1703 & 83 & 1900 & 1593 & 87 & 1804 \\
\hline 3000 & 1897 & 62 & 2046 & 1935 & 61 & 2086 & 1834 & 63 & 1993 \\
\hline
\end{tabular}

